\title{
Chronodisruption and Obesity
}

\author{
Anna Meiliana ${ }^{1,2, *}$, Nurrani Mustika Dewi ${ }^{2}$, Andi Wijaya ${ }^{2,3}$ \\ ${ }^{1}$ Postgraduate Program in Clinical Pharmacy, Padjadjaran University, Jl. Eijkman No.38, Bandung, Indonesia \\ ${ }^{2}$ Prodia Clinical Laboratory, Jl. Cisangkuy No.2, Bandung, Indonesia \\ ${ }^{3}$ Postgraduate Program in Clinical Biochemistry, Hasanuddin University, J1. Perintis Kemerdekaan Km.10, Makassar, Indonesia \\ *Corresponding author. E-mail: anna.meiliana@prodia.co.id
}

Received date: Aug 19, 2015; Revised date: Sep 11, 2015; Accepted date: Nov 5, 2015

\section{Abstract}

$\mathrm{B}$ ACKGROUND: Attempts to understand the causes of obesity and develop new therapeutic strategies have mostly focused on caloric intake and energy expenditure. Recent studies have shown that the circadian clock controls energy homeostasis by regulating circadian expression and/or activity of enzymes, hormones, and transport systems involved in metabolism. Moreover, disruption of circadian rhythms leads to obesity and metabolic disorders.

CONTENT: Regularly alternating periods of light and darkness, such as normally occur with the rising and the setting of the sun, are essential for the maintenance of undisturbed circadian rhythms in all organisms including humans. The light-dark environment, as detected by specialized photoreceptors in the retinas, impacts the endogenous circadian clock in the anterior hypothalamus, the suprachiasmatic nuclei. These nuclei, via both neural and humoral signals, communicate with cells throughout the organism to establish regular circadian rhythms. The introduction of artificial sources of light roughly 150 years ago has significantly undermined the naturally occurring light-dark environment and, likewise, has disturbed circadian rhythms since light is now available at unusual times, i.e., at night. Light at night is known to cause circadian disruption and melatonin suppression. Many potentially pathophysiological consequences of these artificial lightmediated changes, include cancer, cardiovascular diseases, insomnia, metabolic syndrome, diabetes, and cognitive disorders may be aggravated by the increased exposure to light at night, which is inevitable in well-developed societies that have undergone extensive electrification.

SUMMARY: Therefore, it is plausible that resetting of the circadian clock can be used as a new approach to attenuate obesity. Feeding regimens, such as restricted feeding, calorie restriction and intermittent fasting, provide a time cue and reset the circadian clock and lead to better health. In contrast, high-fat diet leads to disrupted circadian expression of metabolic factors and obesity.

KEYWORDS: obesity, circadian clock, metabolism, chronodisruption

Indones Biomed J. 2015; 7(3): 117-28

\section{Introduction}

If the current trend continues as predicted, health care systems may be incapable of handling the myriad of obesity-related diseases. The financial costs, including those due to medical procedures, absenteeism from work, and reduced economic productivity, will jeopardize the financial well-being of industries.(1) Making matters worse, obesity is no longer an affliction limited to adults but it now affects the adolescent and younger populations as well. $(2,3)$ Indeed, childhood obesity has become rampant, and, as a consequence, children are acquiring diseases and disorders that were typically only common in adults a couple decades ago. Moreover, humans have inflicted the obesity state on their pets as a result of over-feeding and by limiting their activity.

Obesity has become a serious and growing public 
health problem (1), but previous ways to combat obesity have failed, and new approaches need to be taken. Just like music has rhythm, lots of our daily lives aspects also have a regular timing for eating and fasting, sleeping and wakefulness. This second nature of our body were governed by an intricate system known as internal molecular clocks, which coordinating and maintaining the synchrony of body biological process between the environmental cycles of light and nutrients. The circadian system, as our body's internal clock is a complex feedback network that keeps us in orchestrated sync with the 24 hours earth's rotation. It involves the interaction between nervous system and peripheral tissues, linked to metabolic homeostasis, and conversely, having feedback signals from metabolic that modulate the expression and behavior of circadian gene.(4)

Social opportunities and work demands have caused humans to become increasingly active during the late evening hours, leading to a shift from the predominantly diurnal lifestyle of our ancestors to a more nocturnal one. This voluntary decision to stay awake long into the evening hours leads to circadian disruption at the system, tissue, and cellular levels. These derangements are in turn associated with clinical impairments in metabolic processes and physiology.(5)

In this review, we consider the potential role that the circadian system including the sleep/wake cycle and the melatonin rhythm may play in determining the accumulation of fat. Given that the daily endogenous melatonin cycle with low circulating levels during the day and elevated serum levels at night, along with the fact that light at night suppresses or distorts this regularly recurring rhythm, we proposed that excessive night-time light may contribute to physiological alterations that predispose to obesity. Moreover, circadian disruption and especially shortened daily sleep intervals, independent of the changes in the melatonin cycle, have been suggested to be contributory to metabolic diseases, which accompany obesity. The implication is that circadian disruption or chronodisruption.(1) And the resulting sleep deprivation and relative melatonin deficiency, alone or in combination, may be factors that make humans more likely to gain weight. If this is the case, there may be behavioral adjustments that humans could make to redress, at least partially, the continuing and mounting problem of obesity.

\section{Chronobiology and Metabolism}

Chronobiology, defined as the science that studies the circadian (around a day) rhythms of biological beings, is a relatively new science which was first discovered in the eighteenth century. It came out with Linnaeus, who designed a beautiful "floral clock" that represented the hours of the day depending on the time that flowers open their petals. Among human beings, the circadian rhythms are so inherent to our lives that we do not even notice them. Perhaps this is the reason why in the medical practice the circadian variability of the hormones, metabolites, and physiological behaviors or the relevance of time in the presence or absence of different pathologies has been practically ignored in the past.(6)

The discovery of the Circadian Locomotor Output Cycles Kaput (CLOCK) mutant mouse in 1994 and the identification and cloning of the gene underlying the mutation, named CLOCK, was a landmark finding in the history of the field of mammalian circadian rhythms. Unexpected at the time, the discovery of the CLOCK mutant animal would eventually lead to an entire new approach to the study and treatment of obesity. The report in 2005 that the CLOCK mutant animal is obese and shows signs of the metabolic syndrome (MetS) opened up an entire new field of obesity research.(7) The circadian system of mammals has three main components: circadian clocks, the input pathways, which participate in environmental synchronization (or entraining), and the output pathways, which transmit the temporal circadian signals to the rest of the effector systems of the organism (Figure 1).(7)

In mammals, the principal circadian clock or master pacemaker is located in the suprachiasmatic nuclei (SCN) of the hypothalamus. $(9,10)$ These are two small nuclei composed of several thousand neurons located each side of the third ventricle in dorsal position with respect to the optic chiasm. With their rhythmic activity, the $\mathrm{SCN}$ are responsible for most circadian rhythms of mammals, as revealed by lesion studies, which result in arrhythmicity in most of the variables recorded. In contrast, the transplantation of SCN from donor to arrhythmic SCN-lesioned animals restores the rhythmicity, confirming that the SCN is a circadian pace maker in mammals.(11) Besides the principal hypothalamic pacemaker, the circadian system is composed of numerous secondary oscillators (cerebral cortex, liver, kidney, adipose tissue (AT)), which are capable of producing circadian oscillations and which in normal conditions are under the control of the SCN.(12,13) However, these oscillators can also operate autonomously for several days in tissue cultures and can be synchronized by periodical signals other than light, such as temperature cycles or nutrient availability.

Both in the SCN and in the peripheral oscillators each cell behaves as an autonomous circadian oscillator. At cell level, the circadian oscillators are the result of the existence of positive and negative feedback loops in which the 
products of the expression of given genes inhibit their own transcription, generating a rhythmicity of around 24 hours. (14) The main components that have been identified in the clock of mammals are: the CLOCK and Brain and muscle aryl hydrocarbon receptor nuclear translocator (ARNT)-like protein (BMAL) 1 genes as positive elements, and the period ((PER)1, PER2 and PER3) genes and the cryptochromes ((CRY)1 and CRY2) as negative elements.(15) CLOCK and BMAL1 proteins are transcription factors that possess the functional domain bHLH ("Basic Helix-Loop-Helix") which confer them with a DNA binding capacity. These proteins heterodimerize in the cytoplasm through PAS domains (a name derived from the three proteins they share, PER-ARNT-Singleminded protein (SIM)) and translocate to the nucleus, where they activate the transcription of given target genes (PER, CRY, Rev-Erb $\alpha$ ) and CLOCK Controlled Genes (CCG), including key regulators of the cell cycle and metabolism.(16)

The negative feedback loop comprises the heterodimers PER:CRY which translocate to the nucleus where they suppress their own transcription by inhibiting CLOCK and BMAL1 activities. Meanwhile, the protein Rev-Erbo suppresses BMAL1 transcription by binding to the elements conforming the response to Rev-Erbo/RARrelated orphan receptor (ROR) present in their promoter. Consequently, the RNA levels of BMAL1 diminish, while those of PER and CRY increase. When the heterodimers CRY:PER suppress their own transcription at nuclear level (through acting on CLOCK-BMAL1), they also inhibit the transcription of Rev-Erbo, permitting the transcription of BMAL1 to be activated.

The approximately 24 hours rhythmicity of the molecular CLOCK mainly derives from post-translational

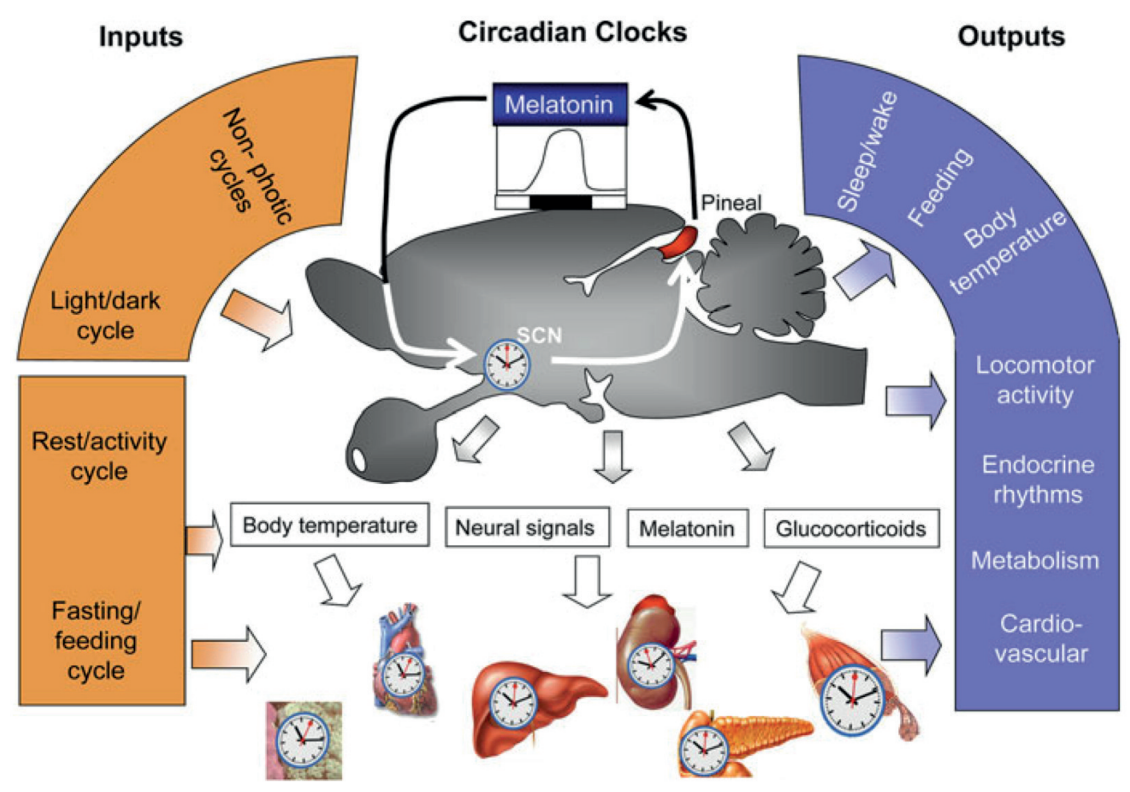

modifications such as phosphorylation and ubiquitination, processes which affect the stability and translocation of the clock genes to the nucleus. In this way, the casein kinase 1 epsilon (CK1ع) and casein kinase 1 delta (CK1 $\delta)$ are critical factors that modulate the functioning of the CLOCK.(17)

Although still in the early stages of discovery, linking circadian clock genes to energy regulation has clear implications for future studies on body weight regulation at the mechanistic level, as well as for the development of new therapeutic approaches for combating the epidemic of obesity, as well as metabolic disorders, including diabetes. (7) Clinical and epidemiological studies have shown the interaction between the circadian system disruption or chronodisruption and some pathologies very frequent in developed countries, such as cancer, obesity, MetS, insomnia, cognitive and affective disorders and premature aging.

\section{AT as A Peripheral Clock}

AT currently known as a complex and highly metabolic endocrine organ, not only functioning as a storage but also express and secrete a variety of bioactive peptides, socalled adipokines, involved in coordinating numerous of biological process including energy homeostasis, adipocyte differentiation, body fat distribution and dyslipidemia, even has an outstanding role as a depot for active circadian clock. (17)

Recent findings showed an expression of CLOCK genes in human AT, responsible to the changes of different component of MetS (18), and this genes has been shown to oscillate SCN accurately and independently in human AT explants (12), participating in regulating the timing of other CCGs such as Peroxisome proliferatoractivated receptor (PPAR)- $\gamma$ and glucocorticoid metabolism genes $(12,19)$. Moreover, these circadian patterns differ between visceral and subcutaneous AT depots.(12,19) Other evidence that suggest a close relationship between circadian rhythms and adipose biology could be the fact that 24 hours rhythms have been reported in the plasmatic concentration of leptin and adiponectin

Figure 1. General organization of mammalian circadian system.(8) (Adapted with permission from Springer). 
in humans $(20,21)$, being both adipokines.

There is a strong correlation between circadian system and AT metabolism, and some evidence showed that this circadian system affecting the alteration of adipocyte sensitivity to specific stimuli (e.g., insulin, adrenaline) and adipocyte intrinsic nature for diurnal variation.(2224) Adipocytes have to adjust the lipogenesis (the rates of triglyceride synthesis) and lipolysis (the rates of triglyceride breakdown) over the 24 hours course simultaneously. These diurnal variations influenced by neurohormonal factors. Some adipocyte-specific factors such as leptin, resistin, adipsin, adiponectin, visfatin, glucocorticoid, showed circadian rhythmicity become a good evidence for AT rhythmicity in mammals.(12) Adiponectin, a protector against MetS disturbances (25), shows the daily pattern of both ultradian pulsatility and a diurnal variation, out of phase with leptin, with a significant decline at night and reaching a nadir in the early morning.(26,27) Emerging evidence from both cell-based and human studies suggests that expression of the circadian clock transcription network within AT may influence both adipogenesis and the relative distribution of subcutaneous versus visceral depots. $(18,28,29)$

In AT, the clock machinery controls the expression of a large array of enzymes involved in lipid metabolism. Indeed, adenovirus-mediated expression of BMAL1 in 3T3-L1 adipocytes resulted in induction of several factors involved in lipogenesis, whereas BMAL1 deletion in adipose cell lines resulted in impaired adipogenesis.(30) Furthermore, heme, the Rev-Erb $\alpha / \beta$ natural ligand, has long been known to enhance adipocyte differentiation in vitro.(31) Activation of sirtuin (SIRT)1, which regulates the clock network, may increase insulin sensitivity and reduce the inflammatory response in adipocytes $(32,33)$, however it is unclear whether the effect is direct or not.(34)

A temporally restricted feeding experiments in mice have revealed a coordinated phase-shift in circadian expression of core clock genes ad their AT downstream targets.(35) In addition, high fat diet (HFD) also alters the cyclic expression and function of core CLOCK genes and CCGs in AT, resulting in disrupted fuel use. $(36,37)$ Of further interest, CLOCK gene disruption targeted to the fat body in flies is sufficient to induce increased food consumption, decreased glycogen levels, and increased sensitivity to starvation.(38) In addition to effects of circadian transcription on intracellular metabolic pathways, clock dysregulation in AT and/or misalignment with meal times may lead to inappropriate expression patterns of enzymes involved in lipid metabolism such as lipoprotein lipase.(28) For example, misalignment between the fasting/feeding cycle and lipogenic and/or lipid catabolic gene expression pathways may perturb fatty acid flux and contribute to lipotoxicity. Indeed, circadian synchrony may play a distinct role not only within different tissue types (liver versus muscle) but also within distinct adipose depots (visceral versus subcutaneous).(12) It is further possible that differences of circadian gene expression patterns within visceral AT and subcutaneous AT depots may contribute to cell-autonomous differences in inflammatory, lipogenic, and/or lipolytic pathways within these locales. $(39,40)$ The limited storage-capacity of fat and/or increased lipolysis results in an overflow of fatty acids to ectopic sites such as liver, muscle, and islets.(41,42) Interestingly, both have been proposed to be involved in the etiology of the MetS. $(43,44)$

Circadian regulation may extend to effects within AT on endoplasmic reticulum (ER) stress, an important component of the inflammatory response in this tissue. (45) Obesity results in conditions that increase demand on the ER in metabolic tissues including liver, adipocytes and pancreas, resulting in a persistent inflammatory state. For example, accumulation of reactive oxygen species (ROS), which are abundantly produced by both the ER and the mitochondria during conditions of stress are increased in metabolic organs in MetS. $(45,46)$ In AT, ER stress is involved in adipogenesis and adipokine oversecretion. $(47,48)$ Interestingly, the ER chaperone protein, binding immunoglobulin protein (BiP), a key protein involved in the ER stress response, is expressed in a circadian manner in flies. It has also been reported that CLOCK genes may influence the production of ROS. $(4,49,50)$ Thus, disrupted synchrony of stress response gene expression may alter adipose function and thereby directly contribute to insulin resistance (IR). ER stress may also be induced in brain following high fat feeding, thereby contributing to leptin resistance (51) and perhaps circadian and sleep disturbances $(34,52)$. Thus, any adequate temporal order in these genes daily pattern implicated in AT metabolism could affect not only in body fat distribution, but also have important consequences to alter the obesity-related metabolism. We still need further investigation to provide insight into the metabolic disease etiology and the physiology of energy homeostasis.

\section{Melatonin and Cortisol as Circadian Markers}

One obvious cycle that clearly depends on the prevailing light-dark cycle and the function of the $\mathrm{SCN}$ is the melatonin rhythm. All vertebrate species, regardless of their specific 
circadian activity pattern, experience elevated pineal melatonin production and secretion during the night, with minimal synthesis during the day. As a result, melatonin is often referred to as the 'chemical expression of darkness'. (53) Since pineal melatonin is quickly released once it is produced, the melatonin rhythm in the blood reflects its synthesis within the pineal gland. The melatonin cycle has a number of essential physiological actions. One important function is to apprise cells in the organism as to whether it is day or night, with the cells then using this information to adjust their metabolic activity accordingly.(54) Thus, although the SCN has alternative means in addition to the melatonin cycle for signaling light or darkness at the cellular/organ level, there is little doubt that the fluctuating melatonin levels play an important role in conveying essential timing information to many organs.(1)

The metabolic pathway of tryptophan that culminates in melatonin generation is well known. The quantity of serotonin in the gland is determined by the activity of tryptophan hydroxylase (TPH). The expression of TPH mRNA as well as the activity of the enzyme vary over a light-dark cycle and are clock-driven rhythms; peak levels of both occur at night, coincident with maximal melatonin generation.(55) Whereas the rate of melatonin synthesis from serotonin is generally considered to be coupled to the activity of arylalkylamine N-acetyltransferase (AANAT) (56), there are times when this may not be the case (57). It is usual that the rhythm of pineal AANAT runs in parallel with that of pineal and blood melatonin levels with all three parameters exhibiting peak levels at night. Thus, it is generally accepted that the concentrations of melatonin in the peripheral circulation can be used as an index of the metabolic activity of the pineal gland at virtually the same time.(58)

The essential nature of melatonin synthesis in the pineal gland is that its rhythm provides all species with a circadian melatonin signal which is essential for a number of the physiological effects of this functionally diverse molecule.(58) A large body of evidence supports the key role of endocrine rhythms in the peripheral oscillator physiology. Numerous hormones display circadian rhythms, and many of them depend, directly or indirectly, on the rhythmic SCN output.(59-63) Within the hormonal network, high circadian amplitudes are especially found in several hypophyseal hormones, in glucocorticoids and in melatonin, so that their respective signaling mechanisms should be of utmost importance for optimal peripheral phase relationships.(64) The requirement of melatonin for the maintenance of robust circadian rhythms is even evident in the peripheral oscillator of the adrenal cortex, a tissue that is otherwise strongly influenced by the adrenocorticotropic hormone (ACTH) rhythm.

The requirement of melatonin for maintaining specific, and presumably favorable, phase relationships between oscillators in the central nervous system and in peripheral organs implies that disturbances, deficiencies, and disorders of melatonin secretion should have profound influences on the functioning of the entire circadian oscillator system. This would include light at night, for example, because of shift work, age- or disease-dependent decreases of melatonin, and congenital atypical secretion patterns as well (Figure 2). With regard to the rapidly accumulating evidence for the importance of a well-functioning circadian oscillator system in maintaining an optimal health status, and to the remarkable complexity of this system composed of numerous, potentially variably coupled central and peripheral oscillators, the role of melatonin as an internal coupling agent may require redefinition and gain significance. This would be in addition to known health-relevant effects concerning, for example, immunomodulation, antiinflammatory, antiexcitatory, and oncostatic actions, as well as antioxidative protection by melatonin. Moreover, melatonin-controlled phasing and coupling may turn out to be essential components in all these areas of protection.(64)

In the circadian orchestra, different biological rhythms are the output of SCN.(66,67) Thus, for example, melatonin peaks during the night in response to nocturnal activation by SCN of the limitant enzyme AANAT in the pineal gland, while cortisol peak should occur in the morning in response to suprarenal activation by ACTH, which in turn, is under SCN control.(68) When the orchestra is out of tune within our body, we talk about chronodisruption.(65)

One easily measurable rhythm that is obviously disordered by alterations of the circadian clock is the sleep/ wake cycle. This is readily seen in the phenomenon of 'jet lag'.(69) Performing rapid transmeridian travel across multiple time zones, particularly in an easterly direction, requires the SCN to readjust its signal to the new light: dark environment after arrival. During this period of readjustment, individuals experience sleep disturbance, increased fatigue and general malaise, i.e., 'jet lag', with conspicuous disturbances in the 24 hours melatonin cycle. (70)

The pineal hormone, melatonin, is a messenger of the light-dark alternation in our environment and is thought to serve as synchronizer for circadian rhythms and seasonal variations. Its circadian periodicity may be understood as a coordinating signal for other biological rhythmicities, or as an "endogenous synchronizer".(71) Plasma melatonin levels have been shown to be a good biomarker of circadian 
dysregulation and have been associated with shift work and exposure to light-at-night in both laboratory-based and field studies. Among other circadian markers, rhythms (such as core body temperature) remain comparatively robust in the presence of various external influences.(72)

Melatonin is considered the best marker of the circadian system phase. However, its profile is strongly influenced by light exposure and, to a lesser extent, body position, physical activity, sleep, caffeine and drugs like non-steroidal anti-inflammatory drugs (NSAIDS) and beta-blockers.(73-79) Plasma levels of melatonin show a circadian profile, with low levels during the day and high levels during the night, the highest being between 02:00 and 04:00 a.m. In humans, melatonin contributes to the body temperature rhythm since it is responsible for vasodilatation of the skin of the extremities through its activation of thermosensitive neurons present in brain areas involved in sleep regulation. The melatonin secretion schedule is closely related with the propensity to sleep and coincides with a fall in the central body temperature, arousal level and performance.(80) The levels of melatonin can be reliably measured in plasma, saliva and urine (in the last case as its metabolite, 6-sulfatoximelatonin). The best time to evaluate melatonin as a marker of the circadian rhythm coincides with its rapid increase at nightfall. Since its levels are altered by exposure to environmental light of a given intensity and spectrum, it is generally accepted that melatonin samples taken during the dark period should be collected under a $\operatorname{dim} \operatorname{light}(<50 \mathrm{~lx})(81)$, which is why this protocol is known as DLMO (Dim Light Melatonin Onset). It is sufficient to start sampling 2-3 hours before the subject's normal bedtime (around 19:30-22:00), assuming that the individual shows no phase alterations.(17)

Cortisol is a corticosteroid with a robust circadian

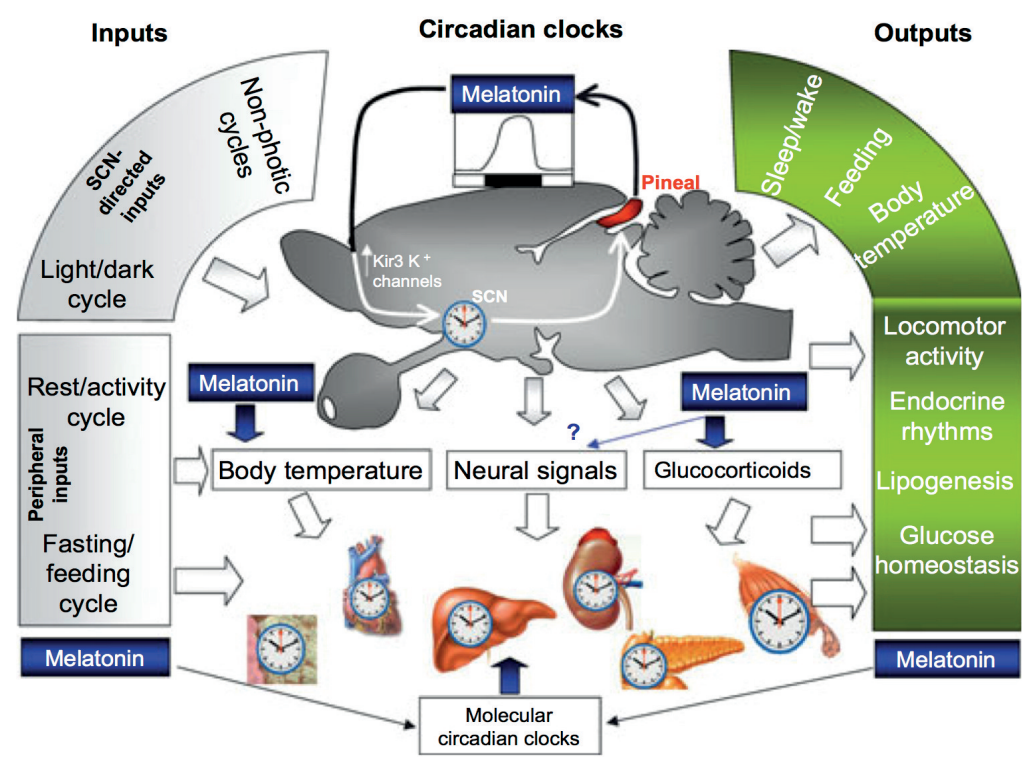

profile, peaking around the usual waking time and with much lower values as the day progresses and reaching its lowest value about 2 hours after going to sleep. The physiological significance of this increase consists of preparing the body for the forthcoming days, increasing the blood pressure, plasma concentrations of glucose, cardiac output, etc. Because of its robustness, this rhythm is also considered a good marker of the circadian system. Similarly to the other variables mentioned above, cortisol levels can be affected by external factors such as stressful situations, light exposure at given moments of the day (82), or hyperproteic meals (83). Non-pathological situations such as aging also affect the cortisol profile.(84) The sleep-wake profile can even modify cortisol rhythm. Sleep deprivation, the predominance of light sleep, and a certain number of nocturnal awakenings will increase cortisol levels.(85) Cortisol can be measured in serum or saliva, the most critical times for measuring its circadian profile being the increase just before waking up and its minimum level in blood at the end of the day/ beginning of night.

The effects of melatonin on brown AT (BAT) may be attributed to both its central and/or peripheral activities. It is well known that BAT is readily regulated by neurons of the hypothalamus, especially, the SCN.(86-88) Membrane melatonin receptors are found in SCN.(89) Environmental information such as photoperiodic alterations change the melatonin message that is conveyed to the SCN. $(90,91)$ Melatonin membrane receptors, especially the $\mathrm{MT}_{1}$, have been found in SCN.(92-94) With the aid of retrograde transneuronal viral tract tracer methods, the anatomical pathway connecting of SCN to BAT was identified as involving the sympathetic nervous system.(95) Thus, Bartness, et al., hypothesize that the thermogenic effects of BAT induced by the melatonin rhythm in the Djungarian hamster is related to an increased sympathetic neural outflow.(96) Simply, the stimulation of the $\mathrm{MT}_{1}$ receptors located on $\mathrm{SCN}$ neurons increases the sympathetic drive in several peripheral tissues that may also include BAT. As a consequence, melatonin acting on $\mathrm{SCN}$ increases noradrenaline turnover, gene expression of uncoupling protein (UCP)1, PPAR- $\gamma$, PPAR- $\gamma$ co-activator-1 (PGC1) in BAT. UCP1 is a unique protein that allows BAT to function in nonshivering thermogenesis.

Figure 2. Overview of the roles of melatonin in the circadian multioscillator system.(65) Kir3: Cardiac inward rectifier 3. (Adapted with permission from Wiley \& Sons) 
PPAR- $\gamma$ and PGC $1 \alpha$ are key factors for brown adipocyte differentiation, and they are also stimulators of mitochondrial biogenesis (important in BAT, which is brown because of the presence of cytochromes in their numerous mitochondria). (97)

Nocturnin (Noc) is a robustly rhythmic gene that encodes a deadenylase thought to be involved in the removal of polyA tails from mRNAs. Mice lacking the Noc gene suggest in part to reduce lipid trafficking in the small intestine thus be resistance to diet-induced obesity and hepatic steatosis. In other tissue, Noc appears to play important roles in lipid metabolism, adipogenesis, glucose homeostasis, inflammation and osteogenesis, also is a potential key post-transcriptional mediator in the circadian control of many metabolic processes.(98)

\section{Sleep, Why Do We Need It?}

Why do we need it? Why do we spend so much of our life doing it? And what is this strange alternative reality we experience while we sleep? These big questions still loom large, but researchers have been focusing on more practical matters. We now know how an intricate interaction of neurotransmitters in different parts of the brain switches us from being fully alert to unconscious, and back again.(99) But the brain does not shut down, studies of its electrical activity are revealing how sleep boosts learning, providing tantalizing clues to the formation of memory.(100)

A night's sleep has five distinct phases, which the brain cycles through roughly every 90 minutes. In rapid eye movement (REM) sleep, the brain's electrical activity looks much as it does when someone is awake. Researchers assumed that REM was when dreams took place, and that in dreams, perhaps, memories are consolidated, the brain replaying the day's experiences and storing them as enduring recollections.(100) Sleep is proving important for more than the mind. Studies that restrict the duration and quality of sleep show that lost sleep can lead to metabolic disorders, immune dysfunctions and chronic disease. (101) And researchers are probing the link between sleep disruption and weight gain.(102)

Mullington and her colleague Monika Haack later found that limiting participants' sleep to 4 hours per night for 12 nights can affect the immune system too. (103) Towards the end of the experiment, sleep-deprived individuals showed elevated blood levels of the immune signaling molecules interleukin (IL) and C-reactive protein (CRP), both of which have been linked to inflammatory problems such as coronary artery disease.(101)
Too much sleep can also be a problem, though. In 2009, Sanjay Patel and Susan Redline, both now at the Brigham and Women's Hospital in Boston, Massachusetts, showed that people who say they sleep more than 8 hours per night have elevated blood levels of IL-6, CRP and tumor necrosis factor (TNF)- $\alpha$, another cytokine involved in systemic inflammation.(104) The interaction between sleep and metabolism is complicated by the poorly understood relationship between sleep and the body's natural circadian rhythms. If you disrupt circadian rhythmicity, you're going to have effects on the sleep-wake cycle, and if you disrupt the sleep-wake cycle, you're probably having effects on various circadian rhythms as well.(102) But there is mounting evidence that getting the right amount of healthy sleep can be just as important as diet and exercise in controlling your metabolism, and can do a world of good beyond making you wake up happy in the morning.(102)

At the root of many sleep problems is the way modern life, especially the advent of artificial light, has decoupled humans from the natural world, disrupting the brain's master clock.(105) Projects are underway to track this desynchronization and reveal how people differ in their tendency to sleep.(106) A lack of sleep can have pernicious effects in those with a mood disorder, and understanding why should help them manage these conditions.(107)

\section{Chronodisruption, Obesity, and MetS}

In several conditions such as jetlag, shift work, light at night, or social jet lag the normal phase relationship between 24 hours environmental cycle with the internal circadian rhythms can be broken down. A relevant disturbance of physiological and behavioral circadian rhythms as a temporal disorder lie this defined as circadian disruption. (108) In addition clock gene polymorphisms and aging may have also chronodisruptive effects. Thus, circadian disruption can be induced by any impairment of the inputs, oscillators and outputs (Figure 3).

Jet lag and rotating shift-work are two well documented factors inducing chronodisruption. These two factors share a common mechanism in the circadian disruption generation involving the differential rates for biological variables synchronization. This may be the result of the different contribution of SCN and peripheral oscillators to the generation of biological rhythms in different variables. For example, following a 6 hours phase delay, the acrophase of ACTH and cortisol rhythms need up to 7 days to resynchronize, while it takes only 3 days in the case of sleep-wake cycle. Thus, during these time, 
there's a different rate shifting for each function, therefore the organism has to re-organized in order to accomplish its efficient functions back.(108) This condition is even more serious in the case of shift-workers because its chronic character. Circadian disruption can also be produced by the impairment of the molecular machinery of the circadian clock; however, discerning the relative influence of disrupted circadian rhythms induced by clock gene alteration from the potential pleiotropic effects of core CLOCK gene inducing pathological process will therefore be a challenge.(110) Some specific disease was associated with CLOCK genes alteratrion, such as premature aging, cancer, and obesity among others.(111)

In the situation where light is extended into the normal period of darkness and light exposure also occurs in the morning before sunrise, the SCN must adjust its signaling processes accordingly; one result of this imposed artificial light is a shortening of the nightly duration of melatonin production by the pineal gland.(112) Thus, in highly industrialized societies, humans have become relatively melatonin deficient since they truncate the normal period of darkness and, thereby, the duration of elevated melatonin. In general, the only time humans are in darkness is when they sleep. Thus, depending on their nightly sleep duration, which is also becoming progressively shorter in developed societies $(113,114)$, the total amount of melatonin produced may be reduced by $50 \%$ or more relative to what would have been generated had they been exposed to the natural light-dark cycle. Given the multiple beneficial actions of melatonin, a $50 \%$ loss of the total amount of melatonin nightly would be expected to have consequences, including negative effects, i.e., pathologies. $(109,115,116)$

Recent studies link energy regulation to the circadian clock at the behavioral, physiological, and molecular levels (117-119), emphasizing that the timing of food intake itself may play a significant role in weight gain (120). The mammalian circadian clock influences nearly all aspects of physiology and behavior, including sleep-wake cycles, cardiovascular activity, endocrine system, body temperature, renal activity, physiology of the gastrointestinal tract, and hepatic metabolism.(13)Disruption of circadian coordination may be manifested by hormone imbalance, psychological and sleep disorders, cancer proneness, and reduced life span.(13,121-124) In contrast, robust circadian rhythms lead to well-being and increased longevity. $(125,126)$ This correlation reveals the prominent influence of the circadian clock on human physiology and pathophysiology.

A major problem with the activities of modern humans is that we are living a twenty-first century life-style with an ancient genome, which is not compatible with the artificially altered photoperiods. Thus, humans have corrupted the fundamental circadian physiology by polluting night-time darkness with light. This extraordinary perturbation of the regularly recurring light-dark environment, a cycle which has existed throughout human evolution, has negative consequences on the most critical functions of the SCN and all peripheral oscillators. Over millions of years of evolution, humans (indeed, all animals) became physiologically dependent on the stable changes in day and night and, in fact, vertebrates evolved a clock, the SCN, to use the lightdark cycle to their advantage.(1)

It is not surprising that these drastic changes in the environment would lead to metabolic disturbances. Karlsson and co-workers conducted a large epidemiological study of the association of shift work with metabolic disorders and found these individuals typically had an increased incidence of general obesity, abdominal obesity, hyperglyceridemia, depressed high-density lipoprotein, diabetes, and cardiovascular abnormalities.(127) This population-based study included 27,485 individuals. The findings clearly showed that the excessive weight gain is not the only disorder that accompanies chronic shift work, but also the expected co-morbidities that are a consequence of obesity were present.(1)

Within the last decade, the dependence of metabolism on the circadian system has been intensively

Figure 3. Causes and consequences of chronodisruption. Circadian disruption is the result of an abnormal phase relationship between the rhythms regulated by endogenous oscillators (solid line) and activity-controlled physiological processes (dotted line).(109) (Adapted with permission from Springer). 
investigated.(128) A variety of hormones known to be involved in the control of metabolism, e.g., cortisol, insulin, glucagon, and growth hormone; fluctuate in a circadian manner. Circadian mechanisms of cells also regulate some metabolic enzymes such as those related to cholesterol metabolism.(128-130) Moreover, nuclear receptors related to the metabolism of glucose and lipids exhibit circadian rhythms.(131) Fonken and colleagues report concluded that the timing of food intake (rather than the total amount of food consumed, which was not influenced), due to chronodisruption, was critical in mediating the observed increased weight gain.(132) It was speculated that nocturnal illumination led to metabolic abnormalities resulting from circadian rhythm misalignment. Fonken, et al., cited other papers which also showed that metabolic circadian rhythm perturbations including that of the 24 hours melatonin cycle are intrinsically related.(120,133,134) The specific metabolic alterations that in fact occur under conditions of circadian disruption have not, however, been well defined. (1)

Circadian disruption, sleep deficiency, and melatonin suppression have at least one common causative feature, i.e., excessive light exposure including even brief periods of light at night. Indeed, interrupting the normal dark period with a short interval of bright light may be the most disruptive. Certainly, light pollution throughout the world, and especially in the economically well developed and developing nations, where obesity is also the most common, has become a major problem and is a serious concern.(1) A lot of studies focused on the pathophysiological consequences of chronodisruption, and suggested thatc chronodisruption can be considered as a risk factor for obesity development, but very few have been published about developing an

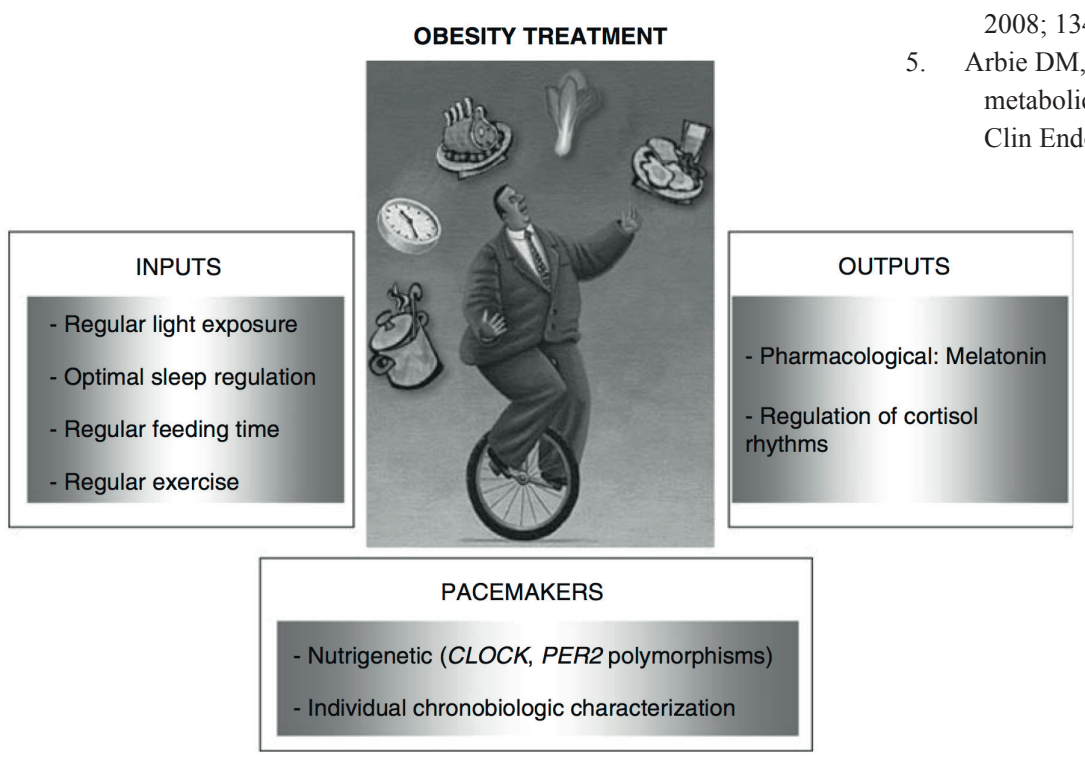

effective strategy to reduce obesity and MetS by resetting the circadian system (chronoenhancement).(111)

There are three levels of potential therapeutic interventions based on the functional organization of the circadian system can be provide for establishing a chronobiological-based therapy for obesity: pacemakers input, pacemakers themselves, and pacemakers output (Figure 4).(108)

\section{Conclusion}

Fluctuations in body weight have been associated with changes in day length in various species, suggesting a central role for the circadian clock in regulating body weight. Thus, it seems that the circadian clock plays a major role in determining body weight probably by influencing the expression and secretion of hormones. Similarly to the control of the circadian clock on metabolism, feeding is a very potent synchronizer (zeitgeber) for peripheral clocks. Resetting the biological clock by food or feeding time may lead to better functionality of physiological systems, preventing metabolic disorders, promoting well-being, and extending life span.

\section{References}

1. Reiter RJ, Tan DX, Korkmaz A, Ma S. Obesity and metabolic syndrome: association with chronodisruption, sleep deprivation, and melatonin suppression. Ann Med. 2012; 44: 564-77.

2. Ogden CL, Flegal KM, Carroll MD, Johnson CL. Prevalence and trends in overweight among US children and adolescents, 19992000. JAMA. 2002; 288: 1728-32.

3. Haslam DW, James WP. Obesity. Lancet. 2005; 366: 1197-209.

4. Green CB, Takahashi JS, Bass J. The meter of metabolism. Cell. 2008; 134: 728-42. disease: findings from animal models. Best Pract Res inol Metab. 2010; 24: 785-800

Figure 4. Different strategies in the treatment of obesity from a chronobiological perspective. (115) (Adapted with permission from Nature Publishing Group). 
6. Garaulet M. Preface. In: Garaulet M, Ordovas JM, editors. Chronobiology and Obesity. New York: Springer; 2013. p.ix.

7. Turek FW. Discovery of the clock mutant and the first mammalian clock gene and the links to obesity: Starting with animal \#25. In: Garaulet M, Ordovas JM, editors. Chronobiology and Obesity. New York: Springer; 2013. p.1-9.

8. Gómez-Abellán P, Garaulet M. Adipose tissue as a peripheral clock. In: Garaulet M, Ordovas JM, editors. Chronobiology and Obesity. New York: Springer; 2013. p.29-53.

9. Moore RY, Eichler VB. Loss of a circadian adrenal corticosterone rhythm following suprachiasmatic lesions in the rat. Brain Res. 1972; 42: 201-9.

10. Stephan FK, Zucker I. Circadian rhythms in drinking behavior and locomotor activity of rats are eliminated by hypothalamic lesions. Proc Natl Acad Sci USA. 1972; 69: 1583-6.

11. Ralph MR, Foster RG, Davis FC, Menaker M. Transplanted suprachiasmatic nucleus determines circadian period. Science. 1990; 247: 975-8.

12. Gómez-Santos C, Gómez-Abellán P, Madrid JA, Hernández-Morante JJ, Lujan JA, Ordovas JM, et al. Circadian rhythm of clock genes in human adipose explants. Obesity. 2009; 17: 1481-5.

13. Guilding C, Piggins HD. Challenging the omnipotence of the suprachiasmatic timekeeper: are circadian oscillators present throughout the mammalian brain? Eur J Neurosci. 2007; 25: 3195216.

14. Ko $\mathrm{CH}$, Takahashi JS. Molecular components of the mammalian circadian clock. Hum Mol Genet. 2006; 15 (Suppl 2): R271-7.

15. Reppert SM, Weaver DR. Coordination of circadian timing in mammals. Nature. 2002; 418: 935-41.

16. Perez JAM. An Introduction to chronobiology. In: Garaulet M, Ordovas JM, editors. Chronobiology and Obesity. New York: Springer; 2013. p.11-28.

17. Lee C, Etchegaray JP, Cagampang FR, Loudon AS, Reppert SM. Posttranslational mechanisms regulate the mammalian circadian clock. Cell. 2001; 107: 855-67.

18. Gomez-Abellan P, Hernandez-Morante JJ, Lujan JA, Madrid JA, Garaulet M. Clock genes are implicated in the human metabolic syndrome. Int J Obes. 2008; 32: 121-8.

19. Hernandez-Morante JJ, Gomez-Santos C, Milagro F, Campion J, Martınez JA, Zamora S, et al. Expression of cortisol metabolismrelated genes shows circadian rhythmic patterns in human adipose tissue. Int J Obes. 2009; 33: 473-80.

20. Sinha MK, Ohanneslan JP, Heiman ML, Kriauclunas A, Stephens TW, Magosin S, et al. Nocturnal rise of leptin in lean, obese, and non-insulin-dependent diabetes mellitus subjects. J Clin Invest. 1996; 97: 1344-7.

21. Gavrila A, Peng CK, Chan JL, Mietus JE, Goldberger AL, Mantzoros CS. Diurnal and ultradian dynamics of serum adiponectin in healthy men: comparison with leptin, circulating soluble leptin receptor, and cortisol patterns. J Clin Endocrinol Metab. 2003; 88: 2838-43.

22. Bartness TJ, Wade GN. Photoperiodic control of body weight and energy metabolism in Syrian hamsters (Mesocricetus auratus): role of pineal gland, melatonin, gonads, and diet. Endocrinology. 1984; 114: 492-8.

23. Zvonic S, Floyd ZE, Mynatt RL, Gimble JM. Circadian rhythms and the regulation of metabolic tissue function and energy homeostasis. Obesity. 2007; 15: 539-43.

24. Bray MS, Young ME. Circadian rhythms in the development of obesity: potential role for the circadian clock within the adipocyte. Obes Rev. 2007; 8: 169-81.

25. Garaulet M, Hernandez-Morante JJ, de Heredia FP, Tebar FJ. Adiponectin, the controversial hormone. Public Health Nutr. 2007;
10: $1145-50$.

26. Gomez-Abellan P, Gomez-Santos C, Madrid JA, Milagro FI, Campion J, Martinez JA, et al. Circadian expression of adiponectin and its receptors in human adipose tissue. Endocrinology. 2010; 151: 11522.

27. Barnea M, Madar Z, Froy O. High-fat diet delays and fasting advances the circadian expression of adiponectin signaling components in mouse liver. Endocrinology. 2009; 150: 161-8.

28. Gimble JM, Floyd ZE. Fat Circadian Biology. J Appl Physiol. 2009; 107: 1629-37.

29. Wu X, Xie H, Yu G, Hebert T, Goh BC, Smith SR, et al. Expression profile of mRNAs encoding core circadian regulatory proteins in human subcutaneous adipose tissue: correlation with age and body mass index. Int J Obes. 2009; 33: 971-7.

30. Shimba S, Ishii N, Ohta Y, Ohno T, Watabe Y, Hayashi M, et al. Brain and muscle Arnt-like protein-1 (BMAL1), a component of the molecular clock, regulates adipogenesis. Proc Natl Acad Sci USA. 2005; 102: 12071-6.

31. Chen JJ, London IM. Hemin enhances the differentiation of mouse 3T3 cells to adipocytes. Cell. 1981; 26: 117-22.

32. Liang F, Kume S, Koya D. SIRT1 and insulin resistance. Nat Rev Endocrinol. 2009; 5: 367-73.

33. Yoshizaki T, Milne JC, Imamura T, Schenk S, Sonoda N, Babendure $\mathrm{JL}$, et al. SIRT1 exerts anti-inflammatory effects and improves insulin sensitivity in adipocytes. Mol Cell Biol. 2009; 29: 1363-74.

34. Maury E, Ramsey KM, Bass J. Circadian rhythms and metabolic syndrome: from experimental genetics to human disease. Circ Res. 2010; 106: 447-62.

35. Zvonic S, Ptitsyn AA, Conrad SA, Scott LK, Floyd ZE, Kilroy G, et al. Characterization of peripheral circadian clocks in adipose tissues. Diabetes. 2006; 55: 962-70.

36. Kohsaka A, Laposky AD, Ramsey KM, Estrada C, Joshu C, Kobayashi Y, et al. High-fat diet disrupts behavioral and molecular circadian rhythms in mice. Cell Metab. 2007; 6: 414-21.

37. Ando H, Yanagihara H, Hayashi Y, Obi Y, Tsuruoka S, Takamura T, et $a l$. Rhythmic messenger ribonucleic acid expression of clock genes and adipocytokines in mouse visceral adipose tissue. Endocrinology. 2005; 146: 5631-6.

38. Xu K, Zheng X, Sehgal A. Regulation of feeding and metabolism by neuronal and peripheral clocks in Drosophila. Cell Metab. 2008; 8: 289-300.

39. Hocking SL, Chisholm DJ, James DE. Studies of regional adipose transplantation reveal a unique and beneficial interaction between subcutaneous adipose tissue and the intra-abdominal compartment. Diabetologia. 2008; 51: 900-2.

40. Tran TT, Yamamoto Y, Gesta S, Kahn CR. Beneficial effects of subcutaneous fat transplantation on metabolism. Cell Metab. 2008; 7: 410-20.

41. Hsu IR, Kim SP, Kabir M, Bergman RN. Metabolic syndrome, hyperinsulinemia, and cancer. Am J Clin Nutr. 2007; 86: s867-71.

42. Savage DB, Petersen KF, Shulman GI. Disordered lipid metabolism and the pathogenesis of insulin resistance. Physiol Rev. 2007; 87: 507-20.

43. Klein S, Allison DB, Heymsfield SB, Kelley DE, Leibel RL, Nonas $\mathrm{C}$, et al. Waist circumference and cardiometabolic risk: a consensus statement from shaping America's health: Association for Weight Management and Obesity Prevention; NAASO, the Obesity Society; the American Society for Nutrition; and the American Diabetes Association. Diabetes Care. 2007; 30: 1647-52.

44. Harris RB, Leibel RL. Location, location, location. Cell Metab. 2008; 7: 359-61.

45. Zhang K, Kaufman RJ. From endoplasmic-reticulum stress to the 
inflammatory response. Nature. 2008; 454: 455-62.

46. Hotamisligil GS. Inflammation and endoplasmic reticulum stress in obesity and diabetes. Int J Obes. 2008; 32 (suppl 7): S52-4.

47. Sha H, He Y, Chen H, Wang C, Zenno A, Shi H, et al. The IRE1alpha$\mathrm{XBP} 1$ pathway of the unfolded protein response is required for adipogenesis. Cell Metab. 2009; 9: 556-64.

48. Shaw PJ, Cirelli C, Greenspan RJ, Tononi G. Correlates of sleep and waking in Drosophila melanogaster. Science. 2000; 287: 1834-7.

49. Kondratov RV, Gorbacheva VY, Antoch MP. The role of mammalian circadian proteins in normal physiology and genotoxic stress responses. Curr Top Dev Biol. 2007; 78: 173-216.

50. Kondratov RV, Kondratova AA, Gorbacheva VY, Vykhovanets OV, Antoch MP. Early aging and age-related pathologies in mice deficient in BMAL1, the core component of the circadian clock. Genes Dev. 2006; 20: 1868-73.

51. Ozcan L, Ergin AS, Lu A, Chung J, Sarkar S, Nie D, et al. Endoplasmic reticulum stress plays a central role in development of leptin resistance. Cell Metab. 2009; 9: 35-51.

52. Scharf MT, Naidoo N, Zimmerman JE, Pack AI. The energy hypothesis of sleep revisited. Prog Neurobiol. 2008; 86: 264-80.

53. Reiter RJ. Melatonin: the chemical expression of darkness. Mol Cell Endocrinol. 1991; 79: C153-8.

54. Reiter RJ. The melatonin rhythm: both a clock and a calendar. Experientia. 1993; 49: 654-64.

55. Sugden D. Comparison of circadian expression of tryptophan hydroxylase isoforms mRNAs in the rat pineal gland using realtime PCR. J Neurochem. 2003; 86: 1308-11.

56. Iuvone PM, Tosini G, Pozdeyev N, Hague R, Klein DC, Chaurasia SS. Circadian clocks, clock networks, arylalkylamine $\mathrm{N}$-acetyltransferase, and melatonin in the retina. Prog in Retin Eye Res. 2005; 24: 433-56.

57. Liu $\mathrm{T}$, Borjigin $\mathrm{J}$. $\mathrm{N}$-acetyltransferase is not the rate limiting enzyme in melatonin synthesis at night. J Pineal Res. 2005; 39: 91-6.

58. Reiter RJ, Tan DX, Fuentes-Broto L. Melatonin: a multitasking molecule. Prog Brain Res. 2010; 181: 127-51.

59. Van Cauter E. Endocrine rhythms. In: Arendt J, Minors DS, Waterhouse JM, editors. Biological Rhythms in Clinical Practice. London: Wright; 1989. p.23-50.

60. Hastings MH. Neuroendocrine rhythms. Pharmacol Ther. 1991; 50: 35-71.

61. Sensi S, Pace Palitti V, Guagnano MT. Chronobiology in endocrinology. Ann Ist Super Sanita. 1993; 29: 613-31.

62. Murphy PJ, Campbell SS. Physiology of the circadian system in animals and humans. J Clin Neurophysiol. 1996; 13: 2-16.

63. Velasco Plaza AM. Variaciones ritmicas del sistema endocrino. In: Madrid JA, Rol de Lama MA, editors. Cronobiologia basica y clınica. Madrid: Editec@Red; 2006.p.447-86.

64. Hardeland R, Madrid JA, Tan DX, Reiter RJ. Melatonin, the circadian multioscillator system and health: the need for detailed analyses of peripheral melatonin signaling. J Pineal Res. 2012; 52: 139-66.

65. Corbalan-Tutau D, Madrid JA, Nicolas F, Garaulet M. Daily profile in two circadian markers "melatonin and cortisol" and associations with metabolic syndrome components. Physiol Behav. 2014; 123: 231-5.

66. Garaulet M, Madrid JA. Chronobiological aspects of nutrition, metabolic syndrome and obesity. Adv Drug Deliv Rev. 2010; 62: 967-78.

67. Feillet CA, Albrecht U, Challet E. "Feeding time" for the brain: a matter of clocks. J Physiol Paris. 2006; 100: 252-60.

68. Garaulet M, Gomez-Abellan P, Madrid JA. Chronobiology and obesity: the orchestra out of tune. Clin Lipidol. 2010; 5: 1818.
69. Zee PC, Goldstein CA. Treatment of shift work disorder and jet lag. Curr Treat Options Neurol. 2010; 12: 396-411.

70. Arendt J. Jet-lag. Lancet. 1998; 351: 293-4.

71. Ferrari E, Fraschini F, Brambill F. Hormonal circadian rhythms in eating disorders. Biol Psychiatry. 1990; 27: 1007-20.

72. Mirick DK, Davis S. Melatonin as a biomarker of circadian dysregulation. Cancer Epidemiol Biomarkers Prev. 2008; 17: 330613.

73. Monteleone P, Maj M, Fusco M, Orazzo C, Kemali D. Physical exercise at night blunts the nocturnal increase of plasma melatonin levels in healthy humans. Life Sci. 1990; 47: 1989-95.

74. Deacon S, Arendt J. Posture influences melatonin concentrations in plasma and saliva in humans. Neurosci Lett. 1994; 167: 191-4.

75. Murphy PJ, Myers BL, Badia P. Nonsteroidal anti-inflammatory drugs alter body temperature and suppress melatonin in humans. Physiol Behav. 1996; 59: 133-9.

76. Stoschitzky K, Sakotnik A, Lercher P, Zweiker R, Maier R, Liebmann $\mathrm{P}$, et al. Influence of beta-blockers on melatonin release. Eur J Clin Pharmacol. 1999; 55: 111-5.

77. Shilo L, Sabbah H, Hadari R, Kovatz S, Weinberg U, Dolev S, et al The effects of coffee consumption on sleep and melatonin secretion. Sleep Med. 2002; 3: 271-3.

78. Zeitzer JM, Duffy JF, Lockley SW, Dijk DJ, Czeisler CA. Plasma melatonin rhythms in young and older humans during sleep, sleep deprivation, and wake. Sleep. 2007; 30: 1437-43.

79. Cardinali DP, Pévet P. Basic aspects of melatonin action. Sleep Med Rev. 1998; 2: 175-90.

80. Dijk DJ, Cajochen C. Melatonin and the circadian regulation of sleep initiation, consolidation, structure, and the sleep EEG. J Biol Rhythms. 1997; 12: 627-35.

81. Van Someren EJ, Nagtegaal E. Improving melatonin circadian phase estimates. Sleep Med. 2007; 8: 590-601.

82. Scheer FA, Buijs RM. Light affects morning salivary cortisol in humans. J Clin Endocrinol Metab. 1999; 84: 3395-8.

83. Slag MF, Ahmad M, Gannon MC, Nuttall FQ. Meal stimulation of cortisol secretion: a protein induced effect. Metabolism. 1981; 30: $1104-8$.

84. Van Coevorden A, Mockel J, Laurent E, Kerkhofs M, L'HermiteBalériaux M, Decoster C, et al. Neuroendocrine rhythms and sleep in aging men. Am J Physiol. 1991; 260: E651-61.

85. Caufriez A, Moreno-Reyes R, Leproult R, Vertongen F, Van Cauter E, Copinschi G. Immediate effects of an 8-h advance shift of the restactivity cycle on 24-h profiles of cortisol. Am J Physiol Endocrinol Metab. 2002; 282: E1147-53.

86. Amir S. Retinohypothalamic tract stimulation activates thermogenesis in brown adipose tissue in the rat. Brain Res. 1989; 503: 163-6.

87. Amir S, Shizgal P, Rompre PP. Glutamate injection into the suprachiasmatic nucleus stimulates brown fat thermogenesis in the rat. Brain Res. 1989; 498: 140-4.

88. Tanida M, Gotoh H, Taniguchi H, Otani H, Shen J, Nakamura T, et $a l$. Effects of central injection of L-carnosine on sympathetic nerve activity innervating brown adipose tissue and body temperature in rats. Regul Pept. 2007; 144: 62-71.

89. Glass JD, Lynch GR. Evidence for a brain site of melatonin action in the white-footed mouse, Peromyscus leucopus. Neuroendocrinology. 1982; 34: 1-6.

90. Turek FW, Losee-Olson SH, Ellis GB. Pinealectomy and lesions of the suprachiasmatic nucleus affect the castration response in hamsters exposed to short photoperiods. Neuroendocrinology. 1983; 36: 3359.

91. Mason R, Rusak B. Neurophysiological responses to melatonin in the SCN of short-day sensitive and refractory hamsters. Brain Res. 
1990; 533: 15-9.

92. Wu YH, Zhou JN, Balesar R, Unmehopa U, Bao A, Jockers R, et al. Distribution of MT1 melatonin receptor immunoreactivity in the human hypothalamus and pituitary gland: colocalization of MT1 with vasopressin, oxytocin, and corticotropin-releasing hormone. J Comp Neurol. 2006; 499: 897-910.

93. Masana MI, Benloucif S, Dubocovich ML. Circadian rhythm of mt1 melatonin receptor expression in the suprachiasmatic nucleus of the C3H/HeN mouse. J Pineal Res. 2000; 28: 185-92.

94. Dubocovich ML, Hudson RL, Sumaya IC, Masana MI, Manna E. Effect of MT1 melatonin receptor deletion on melatonin-mediated phase shift of circadian rhythms in the C57BL/6 mouse. J Pineal Res. 2005; 39: 113-20.

95. Bamshad M, Song CK, Bartness TJ. CNS origins of the sympathetic nervous system outflow to brown adipose tissue. Am J Physiol. 1999; 276: R1569-78.

96. Bartness TJ, Demas GE, Song CK. Seasonal changes in adiposity: the roles of the photoperiod, melatonin and other hormones, and sympathetic nervous system. Exp Biol Med. 2002; 227: 363-76.

97. Tan DX, Manchaster LC, Fuentes-Broto L, Paredes SD, Reiter RJ. Significance and application of melatonin in the regulation of brown adipose tissue metabolism: relation to human obesity. Obes Rev. 2011; $12: 167-88$.

98. Stubblefield JJ, Terrien J, Green CB. Nocturnin: at the crossroads of clocks and metabolism. Trends Endocrinol Metab. 2012; 23: 32633.

99. Peplow M. Structure: the anatomy of sleep. Nature. 2013; 497: S2-3.

100. Smith K. Neuroscience: off to night school. Nature. 2013; 497: S4-5.

101. Dolgin E. Deprivation: a wake-up call. Nature. 2013; 497: S6-7.

102. Owens B. Obesity: heavy sleepers. Nature. 2013; 497: S8-9.

103. Haack M, Sanchez E, Mullington JM. Elevated inflammatory markers in response to prolonged sleep restriction are associated with increased pain experience in healthy volunteers. Sleep. 2007; 30: 1145-52.

104. Patel SR, Zhu X, Storfer-Isser A, Mehra R, Jenny NS, Tracy R, et al. Sleep duration and biomarkers of inflammation. Sleep. 2009; 32: 200-4.

105. Czeisler C. Perspective: casting light on sleep deficiency. Nature. 2013; 497: S13. doi: 10.1038/497S13a.

106. Eisenstein M. Chronobiology: stepping out of time. Nature. 2013; 497: S10-2.

107. Deweerdt S. Mood disorders: the dark night. Nature. 2013; 497: S145.

108. Garaulet M, Ordovás JM, Madrid JA. The chronobiology, etiology and pathophysiology of obesity. Int J Obes. 2010; 34: 1667-83.

109. Alvarez-Garcia V, Gonzalez A, Alonso-Gonzalez C, Martinez-Campa $\mathrm{C}, \mathrm{Cos} \mathrm{S}$. Melatonin interferes in the desmoplastic reaction in breast cancer by regulating cytokine production. J Pineal Res. 2012; 52: 282-90.

110. Bechtold DA, Gibbs JE, Loudon AS. Circadian dysfunction in disease. Trends Pharmacol Sci. 2010; 31: 191-8.

111. Reiter Rj, Liu X, Manchester LC, Rosales-Corral SA, Tan DX, Perez JAM. Processes underlying chronodisruption and their proposed association with illness. In: Garaulet M, Ordovas JM, editors. Chronobiology and Obesity. New York: Springer; 2013. p.55-73.

112. Wehr TA. The duration of human melatonin secretion and sleep respond to changes in daylength (photoperiod). J Clin Endocrinol Metab. 1991; 73: 1276-80.

113. Bass J, Turek FW. Sleepless in America: a pathway to obesity and metabolic syndrome? Arch Intern Med. 2005; 165: 15-6.
114. Reiter RJ, Tan DX, Erren TC, Fuentes-Broto L, Paredes SD. Lightmediated perturbations of circadian timing and cancer risk: a mechanistic analysis. Integr Cancer Ther. 2009; 8: 354-60.

115. Hansen J. Increased breast cancer risk among women who work predominantly at night. Epidemiology. 2001; 12: 74-7.

116. Erren TC, Pepe HG, Reiter RJ, Prekarski C. Chronodisruption and cancer. Naturwissenschaften. 2008; 95: 367-82.

117. Oishi K, Shirai H, Ishida N. CLOCK is involved in the circadian transactivation of peroxisome-proliferator-activated receptor alpha (PPARalpha) in mice. Biochem J. 2005; 386: 575-81.

118. Turek FW, Joshu C, Kohsaka A, Lin E, Ivanova G, McDearmon E, et al. Obesity and metabolic syndrome in circadian Clock mutant mice. Science. 2005; 308: 1043-5.

119. Marcheva B, Ramsey KM, Buhr ED, Kobayashi Y, Su H, Ko CH, et al. Disruption of the clock components CLOCK and BMAL1 leads to hypoinsulinaemia and diabetes. Nature. 2010; 466: 627-31.

120. Arble DM, Bass J, Laposky AD, Vitaterna MH, Turek FW. Circadian timing of food intake contributes to weight gain. Obesity. 2009; 17 : 2100-2.

121. Penev PD, Kolker DE, Zee PC, Turek FW. Chronic circadian desynchronization decreases the survival of animals with cardiomyopathic heart disease. Am J Physiol. 1998; 275: H2334-7.

122. Fu L, Pelicano H, Liu J, Huang P, Lee C. The circadian gene Period2 plays an important role in tumor suppression and DNA damage response in vivo. Cell. 2002; 111: 41-50.

123. Filipski E, King VM, Li X, Granda TG, Mormont MC, Claustrat B, et al. Disruption of circadian coordination accelerates malignant growth in mice. Pathol Biol. 2003; 51: 216-9.

124. Davis S, Mirick DK. Circadian disruption, shift work and the risk of cancer: a summary of the evidence and studies in Seattle. Cancer Causes Control. 2006; 17: 539-45.

125. Hurd MW, Ralph MR. The significance of circadian organization for longevity in the golden hamster. J Biol Rhythms. 1998; 13: 430-6.

126. Karasek M. Melatonin, human aging, and age-related diseases. Exp Gerontol. 2004; 39: 1723-9.

127. Karlsson B, Knutson B, Lindhl B. Is there an association between shift work and having a metabolic syndrome? Results from a populationbased study of 27,485 people. Occup Environ Med. 2001; 58: 74752.

128. Kohsaka A, Bass J. A sense of time: how molecular clocks organize metabolism. Trends Endocrinol Metab. 2007; 18: 4-11.

129. Froy O. The relationship between nutrition and circadian rhythms in mammals. Front Neuroendocrinol. 2007; 28: 61-71.

130. Lapasky AD, Bass J, Kohasaka A, Turek FW. Sleep and circadian rhythms: key components in the regulation of energy metabolism. FEBS Lett. 2008; 582: 142-51.

131. Yang X, Dawnes M, Yu RT, Booboat AL, He W, Straume M, et al. Nuclear receptor expression links the circadian clock to metabolism. Cell. 2006; 126: 801-10.

132. Fonken LK, Workman JL, Walton JC, Weil ZM, Morris JS, Haim A, et al. Light at night increases body mass by shifting the time of food intake. Proc Natl Acad Sci USA. 2010; 107: 18664-9.

133. Fung TT, Hu FB, Yu J, Chu NF, Spiegelman D, Tofler GH, et al. Leisure-time physical activity, television watching, and plasma biomarkers of obesity and cardiovascular disease risk. Am J Epidemiol. 2000; 152: 1171-8.

134. Ruger M, Scheer FA. Effects of circadian disruption on the cardiometabolic system. Rev Endocr Metab Disord. 2009; 10: 24560. 